\title{
Energetic and Exergetic Improvement of Geothermal Single Flash Cycle
}

\author{
Navid Nazari ${ }^{*}$ and Soheil Porkhial ${ }^{a}$ \\ a Faculty of science, Islamic Azad University, Karaj, Iran
}

\begin{abstract}
This paper presents a method for modification of single flash cycle power output. The thermodynamic process of the new method consists of extracting a fraction of hot wellhead geothermal fluid for the purpose of superheating saturated steam entering the turbine. Computer programming scripts were developed and optimized based on mathematical proposed models for the different components of the systems. The operating parameters such as separator temperature, fluid wellhead enthalpy and geothermal source temperature are varied to investigate their effects on both net power output and turbine exhaust quality of the systems. Also, full exergy assessment was performed for the new design. The results of separator temperature optimization revealed that specific net power output of the new design can be boosted up to $8 \%$ and turbine exhaust quality can be diminished up to $50 \%$ as compared to common single flash cycle. In addition, for wells with higher discharge enthalpy, superheating process improve specific net power output even up to $10 \%$. Finally, it was observed that the overall system exergy efficiency was approximately raised $3 \%$.
\end{abstract}

Keywords: Super heater, geothermal energy, single flash cycle, exergy analysis,optimization

Article History: Received January $5^{\text {th }} 2016$; Received in revised form June $2^{\text {th }}$ 2016; Accepted July $3^{\text {rd }} 2016$; Available online

How to Cite This Article: Nazari, N. and Porkhial, S. (2016). Energetic and Exergetic Improvement of Geothermal Single Flash Cycle. Int. Journal of Renewable Energy Development, 5(2),129-138.

http://dx.doi.org/10.14710/ijred.5.2.129-138

\section{Introduction}

Development of human societies are dependent on energy availability, hence, it is vital to find reliable and stable source of global energy demand in future (Dincer 2007). Today, about 86\% of the world's energy production is provided from combustion of fossil fuels like oil, gas and coal. Also, it is predicted that these resources will be the main source of energy production even for future decades (Abas et al. 2015). In respect to limited characteristic of these resources and recent global concerns about climate changes, which resulted from emission of green house gases, substitution of fossil base resources with clean and renewable ones is becoming favorable (Dincer et al. 2012).

Geothermal energy is a clean and reliable source of energy, which can be used either for electricity generation or direct utilization (Phillips 2010). As it is reported, less than $0.5 \%$ of total worldwide installed electrical capacity was generated using geothermal sources in 2010, but it is predicted that the advancement of exploitation technologies will significantly increase this potential in the future (Chamorro et al. 2012).

From the very first use of geothermal energy for electricity generation to date many developments in geothermal power technologies have been applied (DiPippo 2015). However, technologies which were utilized to generate electricity from geothermal resource can be categorized based on three main conversion cycles: dry steam plants operate by high temperature geothermal steam coming from steamdominated resources, flash plants use moderate to high temperature geothermal fluid discharged from liquiddominated resources and binary plants which are best suited for power production from low temperature resources (Coskun et al. 2011). Among available

*Corresponding Author: +98-44320033; mobile: +98-912 2636817

Email: nazari.nvd@gmail.com 
geothermal plants, $43 \%$ of the total installed capacity worldwide is dedicated to single flash power plants, which maybe is as a result of low cost and simple thermodynamic process (DiPippo 2012). Thus, finding new methods and modifications, in order to increase power production rate from single flash cycle is of high interest.

Many studies have addressed maximizing single flash power plants output as a main subject. For example, some of these studies evaluated the effect of optimizing plant-operating parameters such as separator temperature and condenser pressure on total power output (Jalilinasrabady et al. 2012), (Dada et al. 2005). Also additional flashing of geothermal brine could increase total power output up to 35\% (Chamorro et al. 2012). Although utilization of binary cycle combined with single flash is considered to be more suitable where additional flashing of geothermal brine is limited due to silica scaling (Wang et al. 2015). More recent methods focused on hybrid utilization scenarios which make it possible to superheat geothermal steam with heat sources like solar or fossil fuels (Zhou 2014), (Bidini et al. 1998). Superheating of geothermal steam is more interesting because in addition to higher power output, increasing saturated steam temperature reduces the probability of water droplet formation in the last stages of turbine expansion process, which also would reduce turbine failure possibility due to corrosion and erosion (Ahmad et al. 2009). In this regard, Potvin proposed a new simple method for superheating geothermal steam in both single and double flash cycle using heat contained in hot wellhead fluid. This modification increased specific power output of cycles approximately 5\% (Mathieu-Potvin 2013). It seems that, with the addition of a simple heat exchanger and utilization of higher temperature streams for increasing inlet steam temperature of turbine, good improvement of cycle power output can be achieved.

In this paper, the effect of using a new way for superheating saturated steam before entering turbine on energetic and exergetic efficiency of single flash cycle with fluid temperature of $260^{\circ} \mathrm{C}$ was evaluated. In addition, numerical simulation was conducted for fluid temperature in the range of 160 to $260^{\circ} \mathrm{C}$ and effect of increasing brine wellhead enthalpy was investigated. Finally, exergy analysis of each equipment and overall plant for optimum $260^{\circ} \mathrm{C}$ case was performed so as to determine the efficiency of transport and conversion of input exergy to useful work.

\section{Materials and Methods}

\subsection{System description}

Figure 1 shows the simplified process flow diagram and figure 2 shows the corresponding T-S diagram for a proposed single flash cycle with super heater design.
Geothermal fluid flows through the wellhead piping as a saturated liquid (1). Before entering throttling valve, a fraction of wellhead fluid is extracted for superheating of saturated steam (2). The extracted geofluid properties in this state are the same as the hot wellhead liquid. In mainstream, as a consequence of pressure reduction in throttling valve, hot wellhead geofluid flashes into a mixture of saturated liquid and saturated steam (3). In next process, geofluid mixture enters a separator, a vertical cyclone or horizontal type (Zarrouk et al. 2015), where saturated steam and liquid are separated. Liquid phase leaving separator (4) can be used either for additional heat extraction processes or being injected to the ground for the purpose of maintaining pressure of reservoir. Saturated steam after leaving separator is sent to the super heater (5) where its temperature will increase. Superheated steam then is ready to be expanded in turbine and producing mechanical power (6). The mechanical power produced in turbine can be converted to electricity via generator. Finally, exhaust steam from turbine outlet (7) cools down to the ambient temperature in condenser and reinjected into the reservoir (8).

\subsection{Thermodynamic model}

The following working equations were used to perform energy and exergy balance analysis of the system. Mathematical model of the system was developed and solved through Matlab programming script (Matlab 2010). Also, thermodynamic state values were obtained from the commercial software Refprop (REFPROP 2010).

\subsubsection{Energy analysis}

Extraction process

Due to same process condition the extracted fluid properties are the same as the wellhead fluid and can be expressed as:

$P_{2}=P_{1}$

$h_{2}=h_{1}$

Implementing energy balance equations for heat exchanger results in calculation of the wellhead fluid mass flow rate that is required to superheat saturated steam:

$$
\dot{m}_{e x t}=\dot{m}_{s t} \times\left(\frac{h_{6}-h_{5}}{h_{2}-h_{2 \alpha}}\right)
$$




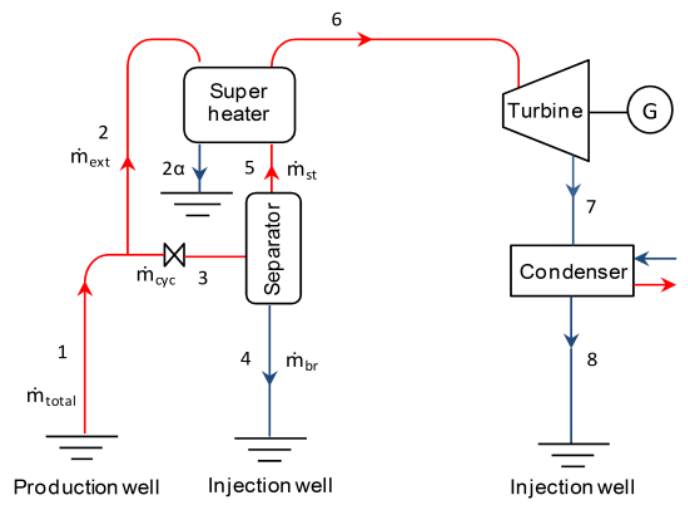

Fig. 1 Simplified process flow diagram of single flash cycle with superheater.

\section{Throttling valve}

As a result of isenthalpic modeling of throttling process, enthalpy of two-phase mixture in this state can be expressed as:

$$
h_{3}=h_{1}
$$

And therefore steam quality of two-phase mixture after flashing can be calculated from the equation given as:

$$
x_{3}=\frac{h_{3}-h_{4}}{h_{5}-h_{4}}
$$

The brine mass flow rate that enters throttling valve can be expressed as:

$\dot{m}_{c y c}=\dot{m}_{\text {total }}-\dot{m}_{\text {ext }}$

\section{Separator}

In this process, it is assumed that no pressure change occurs, so it models as isobaric. The pressure of steam and brine in this state is as follows:

$$
P_{3}=P_{4}
$$

As the temperature of steam and brine is function of separation pressure, therefore:

$T_{3}=T_{4}=T_{5}=T_{\text {sat } @ P_{\text {sep }}}$

Saturated steam and brine mass flow rate can be calculated from below equations:

$\dot{m}_{s t}=x_{3} \times \dot{m}_{c y c}$

$m_{b r}=\dot{m}_{c y c}-\dot{m}_{s t}$

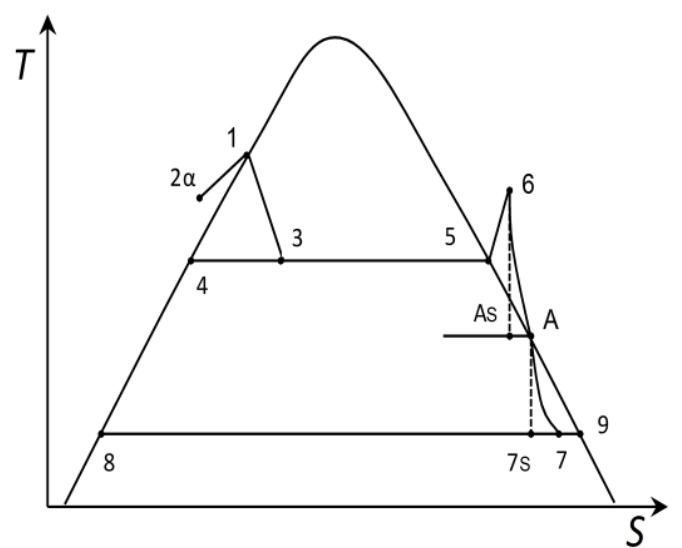

Fig. 2 Temperature-entropy (T-S) diagram of single flash cycle with superheater.

\section{Super heater}

Heat transfer process between extracted wellhead fluid and saturated steam is represented in figure 3. This process causes heating of the saturated steam (5) to the superheated region (6) and cooling of extracted wellhead fluid (2) to the compressed liquid $(2 \alpha)$. The outlet temperature of the superheated steam depends on the heat exchanger efficiency, which is directly affected by minimum temperature difference between hot and cold streams in the heat exchanger. In an ideal heat transfer process, saturated steam with temperature of $T_{5}$, can be superheated to the temperature of hot wellhead fluid, $T_{2}$. But in practical, due to impossibilities, with assuming a minimum temperature difference (pinch point) between hot and cold streams in heat exchanger, temperature of outlet fluids can be calculated.

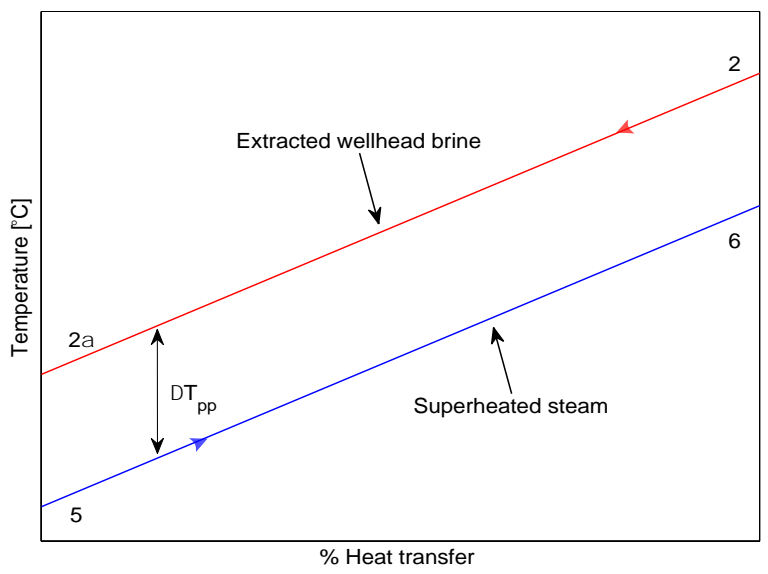

Fig. 3 Diagram for exchanger heat transfer process between hot and cold streams.

The pinch point, $\triangle T p p$, can be located on either the cold or the hot end of the heat exchanger, but due to similar 
temperature and average heat capacity of the streams, the slope of the heating and cooling process is similar and the pinch could appear simultaneously on both ends of the heat exchanger. Outlet fluid temperature of hot and cold side of super heater can be calculated from below equations:

$$
\begin{aligned}
& T_{6}=T_{2}-\Delta T_{p p} \\
& T_{2 \alpha}=T_{5}+\Delta T_{p p}
\end{aligned}
$$

\section{Expansion process}

Expansion process of superheated steam in turbine is divided into two sections, dry expansion region and wet expansion region. In the dry section, superheated steam expands to the state (A) where its quality reaches saturated steam quality, $x_{A}=1$. If expansion process is an isentropic, $S_{6}=S_{A s}$, steam would reach state $(A s)$, where it has lower quality and enthalpy, but due to irreversibility and water droplet formation it just reaches state (A). Steam properties at point (A) can be calculated using turbine dry efficiency, $\eta_{\text {turb }}$. With knowing outlet pressure of the dry section, $\mathrm{P}_{\mathrm{A}}$, where steam expansion reaches to the end of the dry condition, outlet enthalpy of steam, $h_{A}$, can be calculated as:

$$
\eta_{t u r b}=\frac{h_{6}-h_{A}}{h_{6}-h_{A s}}
$$

Therefore, dry section turbine work can be expressed as:

$$
\dot{W}_{d r y}=\dot{\boldsymbol{m}}_{s t} \times\left(\boldsymbol{h}_{6}-\boldsymbol{h}_{A}\right)
$$

After dry expansion, steam expands through the wet region. With fixed condenser pressure, $P_{7}$, and assuming isentropic process, $S_{A}=S_{7 S}$, saturated steam at state (A) would expand to state (7s). However, with respect to irreversibility and water droplet formation, the steam just can be expanded to state (7). Thus, the enthalpy of steam in turbine exhaust of the wet region can be calculated using Baumann's rule given as (DiPippo 2015):

$$
h_{7}=\frac{\left\{h_{6}-A_{2} \times\left[1-\frac{h_{8}}{h_{9}-h_{8}}\right]\right\}}{\left\{1+\frac{A_{2}}{h_{9}-h_{8}}\right\}}
$$

Where $A_{2}$ is given as:

$$
A_{2}=0.425 \times\left(h_{A}-h_{7 s}\right)
$$

And therefore turbine wet section output is given as:
$\dot{W}_{w e t}=\dot{m}_{s t} \times\left(h_{A}-h_{7}\right)$

Total turbine output through expansion from state (6) to (7) can be expressed as:

$\dot{W}_{\text {total }}=\dot{W}_{\text {dry }}+\dot{W}_{\text {wet }}$

Condenser

$\dot{Q}_{\text {cond }}=\dot{m}_{s t} \times\left(h_{7}-h_{8}\right)$

And finally, energy efficiency of the overall plant can be expressed as:

$$
\eta_{I, \text { Plant }}=\frac{\dot{W}_{\text {Total }}}{\dot{Q}_{\text {in }}}
$$

\subsubsection{Exergy analysis}

Exergy analysis can be used as a valuable tool for analysis, design and improvement of energy systems. The exergy method can specify the locations, types and quantities of energy losses in system by applying the conservation of mass and energy principles together with second law of thermodynamics (Rosen et al. 2001).

For this purpose, Table 1 lists all exergy destruction rates and exergy efficiencies, which is defined as the ratio of total exergy output to total exergy input of each system component such as separator, heat exchanger, turbine and condenser for single flash with super heater design. The rate of exergy flow is given by:

$$
\dot{E} X=\dot{m} e x
$$

Where ex $=\left(h-h_{0}\right)-T_{0} \times\left(s-s_{0}\right)$.

And finally, the second law efficiency of the overall plant can be calculated as (Rosen et al. 2004):

$$
\eta_{\text {II,Plant }}=\frac{\dot{W}_{\text {Total }}}{\dot{E} X_{\text {in }}}
$$

\subsubsection{Optimization method}

Net power output of common single flash cycle can be maximized through varying and therefore finding optimum separator pressure (Jalilinasrabady et al. 2012).

In the new design, beside separation pressure, $P_{3}$, the outlet temperature of superheated steam, $T_{6}$, and dry expansion pressure or boundary pressure of expansion where steam from dry region enters wet region, $P_{A}$, should be found. The latter can be calculated using dry efficiency of turbine, $\eta_{\text {turb }}$, and saturated steam quality for state (A), $x_{A}$, as a result of trial and error method. The schematic optimization block diagram is presented in Figure 4. 
Table 1

Expressions of exergy destruction rat and exergy efficiency for each component of the system.

\begin{tabular}{lcc}
\hline Component & Exergy destruction rate & Exergy efficiency \\
\hline Separator & $\dot{E} x_{d, s e p}=\dot{m}_{c y c}\left(e x_{2}\right)-\left[\dot{m}_{s t}\left(e x_{5}\right)+\dot{m}_{b r}\left(e x_{4}\right)\right]$ & $\eta_{\text {ex,sep }}=\frac{\dot{E} x_{4}+\dot{E} x_{5}}{\dot{E} x_{3}}$ \\
Super heater & $\dot{E} x_{d, s h}=\dot{m}_{s t}\left(e x_{5}-e x_{6}\right)+\dot{m}_{e x t}\left(e x_{2}-e x_{2 \alpha}\right)$ & $\eta_{e x, s h}=\frac{\dot{E} x_{6}-\dot{E} x_{5}}{\dot{E} x_{2}-\dot{E} x_{2 \alpha}}$ \\
Turbine & $\dot{E} x_{d, t u r b}=\dot{m}_{s t}\left(e x_{6}-e x_{7}\right)-\dot{w}_{\text {total }}$ & $\eta_{e x, t u r b}=\frac{\dot{w_{t o t a l}}}{\dot{E} x_{6}-\dot{E} x_{7}}$ \\
Condenser & $\dot{E} x_{d, \text { cond }}=\dot{m}_{s t}\left(e x_{7}-e x_{8}\right)$ & $\eta_{e x, c o n d}=\frac{\dot{E} x_{7}-\dot{E} x_{8}}{\dot{E} x_{7}}$ \\
\hline
\end{tabular}

\section{Results and discussion}

This study focused on evaluating the effect of adding super heater on energetic and exergetic efficiencies of a single flash cycle. For this purpose, results of numerical modeling of single flash cycle with super heater were compared with common single flash cycle. The geofluid source temperature and steam fraction of wellhead fluid were varied to see their effect on performance of the system. All pressure losses in all piping and heat exchanger were neglected. The outlet limit for expanded steam quality was also fixed at 0.85 . The other assumptions made in this study are tabulated in table 2 .

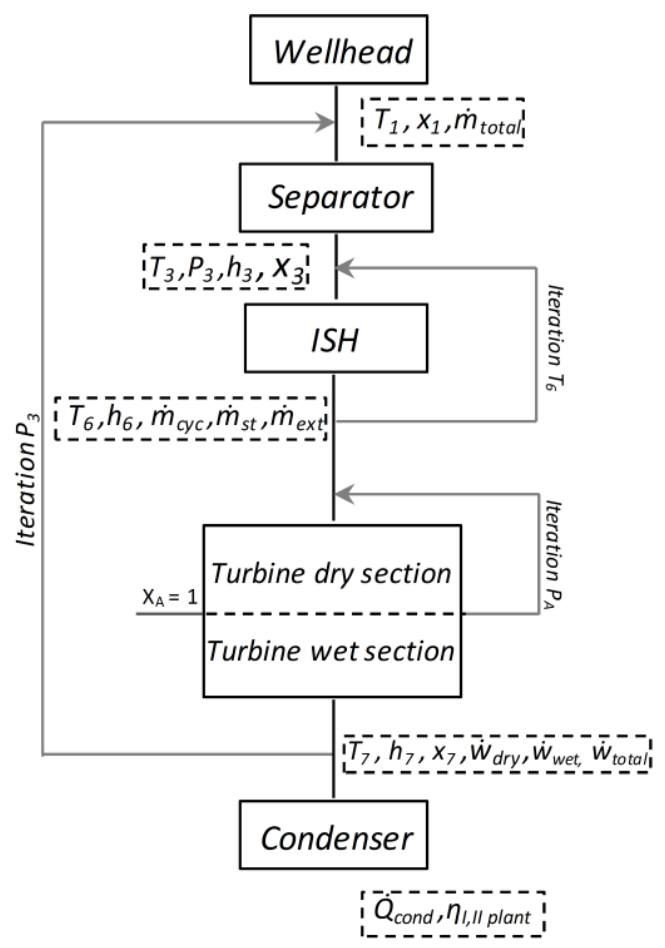

Fig. 4 Optimization block diagram.

\subsection{Effect of separation pressure}

Figure 5(a) shows the specific power output of single flash cycle for different separator pressures. From the Figure, it is evident that increasing separator pressure from 200 to $1600 \mathrm{kPa}$ results in varying net power output of cycle from $103.707 \mathrm{~kJ} / \mathrm{kg}$ to minimum output of $85.908 \mathrm{~kJ} / \mathrm{kg}$. However, separation pressure that corresponds to maximum net power output of $110.080 \mathrm{~kJ} / \mathrm{kg}$ for single flash cycle is $437 \mathrm{kPa}$. A result of numerical simulation of net power output for single flash cycle with super heater across the separator pressure range of 200 to $1600 \mathrm{kPa}$ is shown in figure5(b). In this figure, net power output for dry expansion, wet expansion, and results of total power output, was represented separately. Separator pressure of $200 \mathrm{kPa}$ results for dry, wet and total net power output of $94.911,19.826$ and $114.737 \mathrm{~kJ} / \mathrm{kg}$, respectively. It can be seen that in lower separator pressures dry turbine work has more portion of total net power output, which results in lower boundary pressure of dry to wet expansion, $P_{\text {A. }}$. But with increasing separator pressure and corresponding boundary pressure of dry to wet region expansion, dry turbine work tends to decrease and wet turbine output would increase.

Table 2

Assumptions for numerical simulation.

\begin{tabular}{ll}
\hline Parameters & Values \\
\hline $\mathrm{T} 0$ & $298^{\circ} \mathrm{k}$ \\
$\mathrm{P} 0$ & $100 \mathrm{kPa}$ \\
$\mathrm{T}_{1}$ & $260^{\circ} \mathrm{C}$ \\
$\mathrm{X}_{1}$ & 0 \\
$\dot{\mathrm{m}}_{\text {total }}$ & $1 \mathrm{~kg} / \mathrm{s}$ \\
$\Delta \mathrm{T}_{\mathrm{pp}}$ & $5^{\circ} \mathrm{C}$ \\
$\mathrm{X}_{\mathrm{A}}$ & 1 \\
$\mathrm{P}_{\text {cond }}$ & $10 \mathrm{kPa}$ \\
$\eta_{\text {turb }}$ & 0.85 \\
\hline
\end{tabular}




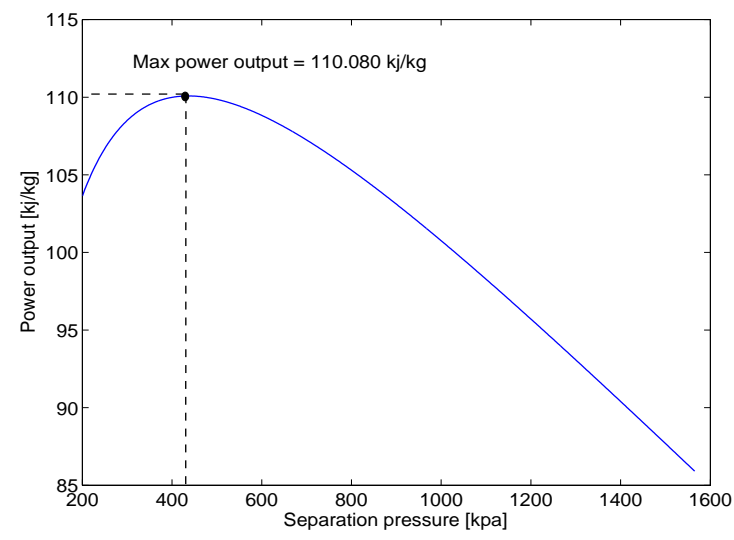

(a)

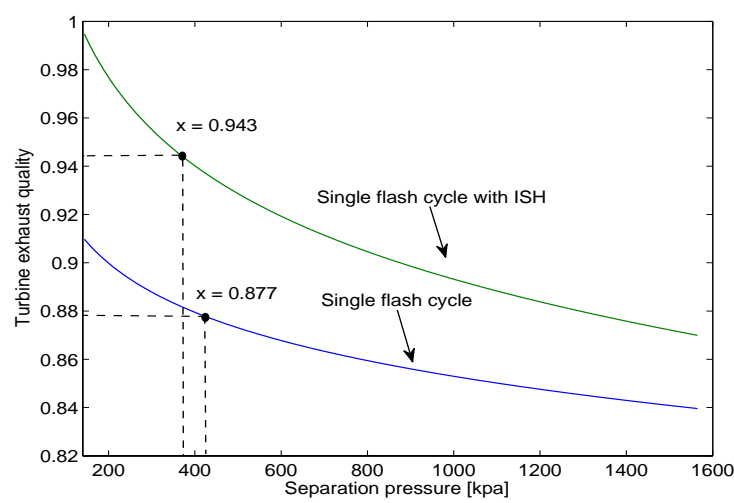

(c)

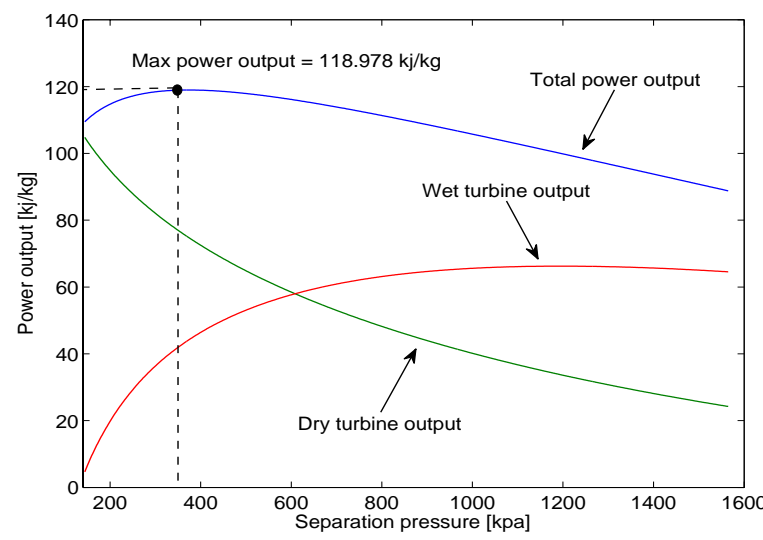

(b)

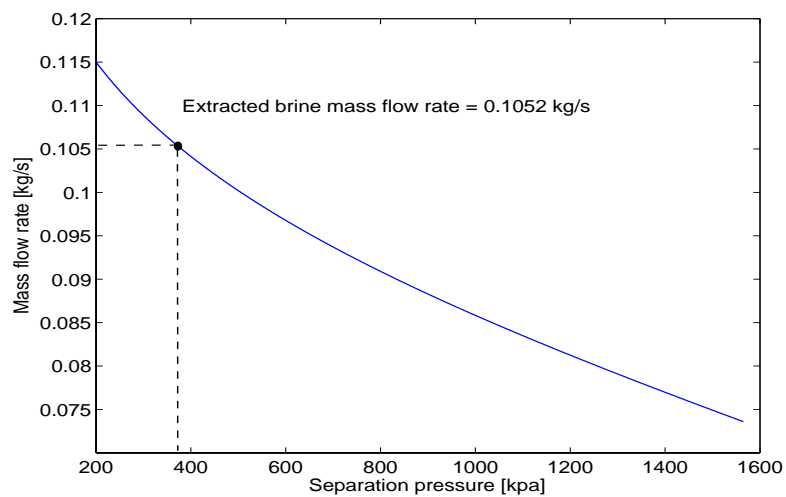

(d)

Fig. 5 Numerical simulation of Single flash and Single flash with super heater. a) Single flash cycle: Specific power out respect to separator pressure. b) Single flash cycle with super heater: Specific power out respect to separator pressure. c) Turbine Exhaust quality respect to separator pressure for both single flash and single flash with super heater. d) Extracted mass flow rate of hot wellhead brine respect to separator pressure for single flash with super heater.

Optimized separator pressure for single flash with super heater design is $375 \mathrm{kPa}$ which corresponds to maximum total power out of $118.978 \mathrm{~kJ} / \mathrm{kg}$. Dry and wet turbine works for this separation pressure are 74.681 and $44.297 \mathrm{~kJ} / \mathrm{kg}$, respectively. It was noticed that adding super heater results in decreasing optimized separator pressure $62 \mathrm{kPa}$ as compared to optimum separator pressure of common single flash. Also, total net power output of new design with super heater gained $8.898 \mathrm{~kJ} / \mathrm{kg}$ or $8.08 \%$ as compared to common single flash cycle design for the base case of $\mathrm{T}_{1}=260^{\circ} \mathrm{C}$. Moreover, turbine steam exhaust quality of common single flash and new design of single flash with super heater across separator pressure range of 200 to $1600 \mathrm{kPa}$ are shown in figure 5(c). It can be seen that adding super heater results in increasing exhaust steam quality of turbine from 0.877 for single flash to 0.943 for new design or $50 \%$ lower moisture on the last stage of expansion which would directly decrease turbine blade erosion and corrosion and related operating and maintenance costs. Finally, figure 5(d) represent extracted mass flow rate of hot wellhead brine that is required to superheat saturated steam across separator pressure range of 200 to 1600
$\mathrm{kPa}$. From the study, it can be concluded that adding super heater results in higher specific power out and turbine efficiency as compared to optimal case of single flash for input parameters tabulated in table 2.

\subsection{Effect of resource temperature}

Here, the effect of varying wellhead geothermal fluid temperature on working parameters of single flash and single flash with super heater design was evaluated. In this regard, net power output of single flash with super heater and common single flash cycle in the range of 160 to $260^{\circ} \mathrm{C}$ for geofluid temperature is illustrated in figure 6(a). In addition, net power gaining percent of single flash with super heater as compared to common single flash cycle is shown in figure 6(a). As can be seen, with increasing geofluid temperature from 160 to $260^{\circ} \mathrm{C}$, net power output of single flash cycle increased from 32.006 to 110.080 $\mathrm{kJ} / \mathrm{kg}$ and net power output of single flash cycle with super heater increased from 33.545 to $118.978 \mathrm{~kJ} / \mathrm{kg}$ or gaining 4.81 to $8.08 \%$ across the different geofluid temperatures when compared to basic single flash. It can be noticed that super heating of saturated steam has greater effect in higher geofluid temperatures. 


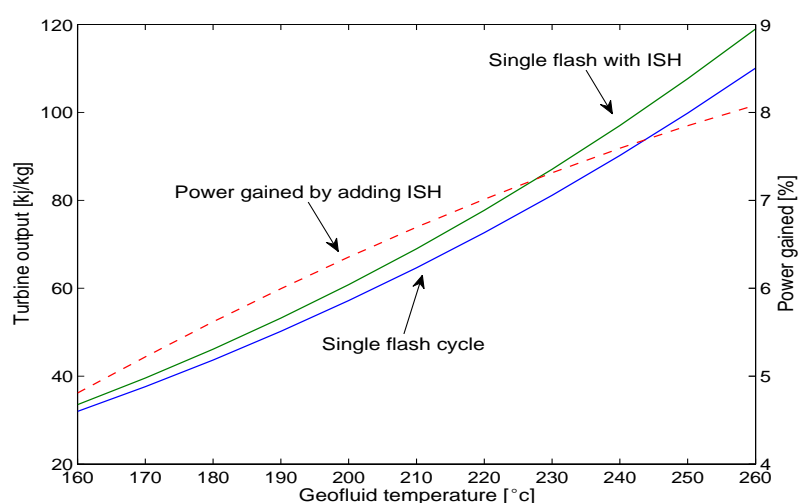

(a)

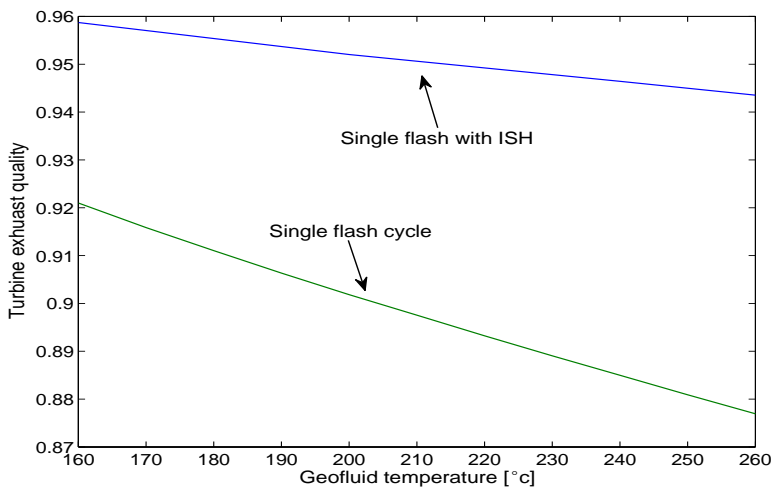

(c)

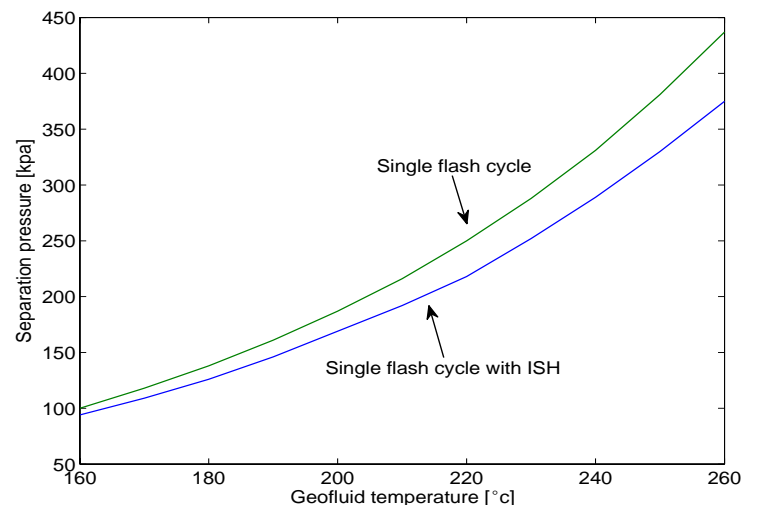

(b)

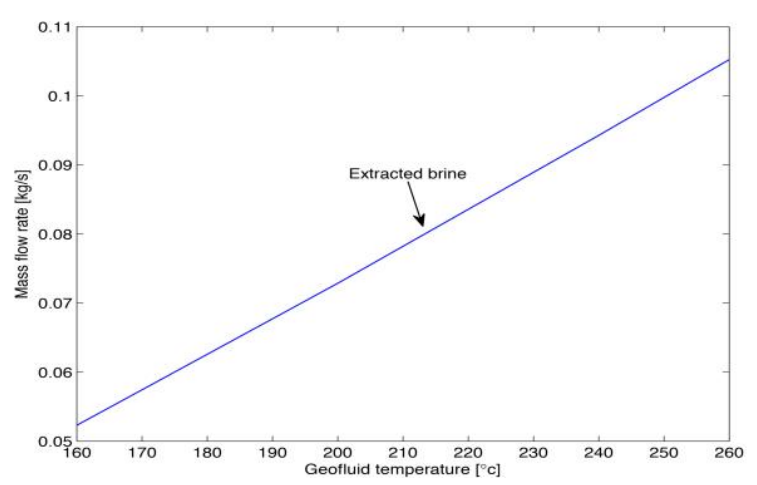

(d)

Fig. 6 Effect of varying wellhead fluid temperature on different operating parameters of single flash cycle and single flash cycle with super heater. a) Maximized net power output. b) Optimized separator pressure. c) Turbine exhaust quality. d) Extracted mass flow rate of hot wellhead fluid.

In addition, the effects of adding super heater on optimized separation pressures and turbine exhaust quality of cycles in different wellhead geofluid temperatures were investigated in figure 6(b) and figure 6(c). Optimized separation pressure varied from 100 to $437 \mathrm{kPa}$ for single flash and from 94 to $375 \mathrm{kPa}$ for single flash with super heater design across wellhead geofluid temperature of 160 to $260^{\circ} \mathrm{C}$. It can be noticed that in the new design, optimized separation pressure is approximately $10 \%$ lower as compared to optimized separator pressure of common single flash cycle. Also, from the figure 6(c) it can be seen that increasing geofluid temperature from 160 to $260^{\circ} \mathrm{C}$ results in varying turbine exhaust quality from 0.921 to 0.877 for single flash cycle and from 0.959 to 0.943 for single flash cycle with super heater which means that turbine exhaust quality of the new design is nearly $6 \%$ higher as compared to common design. This higher quality of turbine outlet stream would decrease possibility of liquid droplet formation on last stage of expansion process and therefore lowers corrosion of the turbine blade.

Finally, extracted mass flow rate required to get maximum net power output for single flash cycle with ISH in respect to optimized separator pressure across geofluid temperature of 160 to $260^{\circ} \mathrm{C}$ is illustrated in figure $6(d)$. As can be seen, increasing geofluid temperature results in increasing mass flow rate of extracted geofluid required to superheat saturated steam leaving separator from $0.052 \mathrm{~kg} / \mathrm{s}$ for $160^{\circ} \mathrm{C}$ to $0.105 \mathrm{~kg} / \mathrm{s}$ for $260^{\circ} \mathrm{C}$.

\subsection{Effect of excess enthalpy}

Some geothermal wells discharge a mixture with higher enthalpy than that of saturated water at reservoir condition. This higher enthalpy of the geothermal mixture is termed excess enthalpy. Phase segregation and conductive heat transfer are considered to be responsible for this phenomenon. When geothermal fluid cools down in reservoir condition as a result of depressurization boiling, conductive heat transfer between reservoir rock and geofluid cause an increase in the steam to water ratio of fluid. Also, due to higher relative permeability of steam compared to water, geothermal well produce a mixture with higher steam fraction and thus enthalpy. Here, the effect of increasing brine wellhead enthalpy on net power output of single flash cycle with super heater design for $260^{\circ} \mathrm{C}$ case was investigated and compared to common single flash cycle. With reference to figure 2 , increasing wellhead fluid steam fraction will cause moving state 3 on T-S diagram to the right and therefore, mass flow rate of saturated steam which leaves separator will increase, but as 
more saturated steam enters super heater, more wellhead fluid should be extracted in order to achieve specified outlet temperature

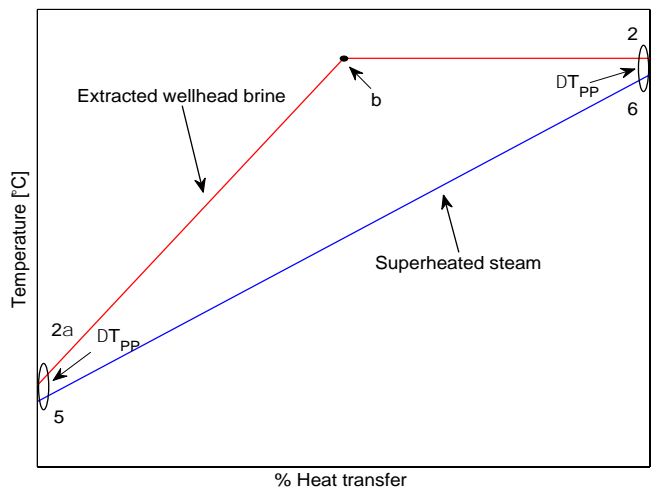

Fig. 7 Heat transfer diagram of exchanger for two phase mixture wellhead fluid.

. Figure 7 shows the effect of increasing steam fraction of wellhead fluid on heat transfer diagram between hot side and cold side of super heater. As it is shown, increasing steam fraction results in moving point (b) to the left and increasing area between two processes that will cause decreasing total power output of new design according to the second law of efficiency. Therefore, the total effect of increasing wellhead steam fraction was not obvious and should be evaluated.

Figure 8 illustrates net power output of common single flash and single flash with super heater design across steam fraction range of 0.1 to 0.6. Excess enthalpy gained by wellhead geofluid as a result of increasing steam fraction from 0.1 to 0.6 was scaled on the bottom axis. In addition, percentage gained power output of new design as compared to single flash is illustrated in this figure too. As it can be seen, with increasing wellhead steam fraction from 0.1 to 0.25 , percent gained power output of new design decreased from 7 to $5 \%$, but in higher steam fractions total net power gained by adding of super heater increased to $10 \%$ as compared to single flash cycle.

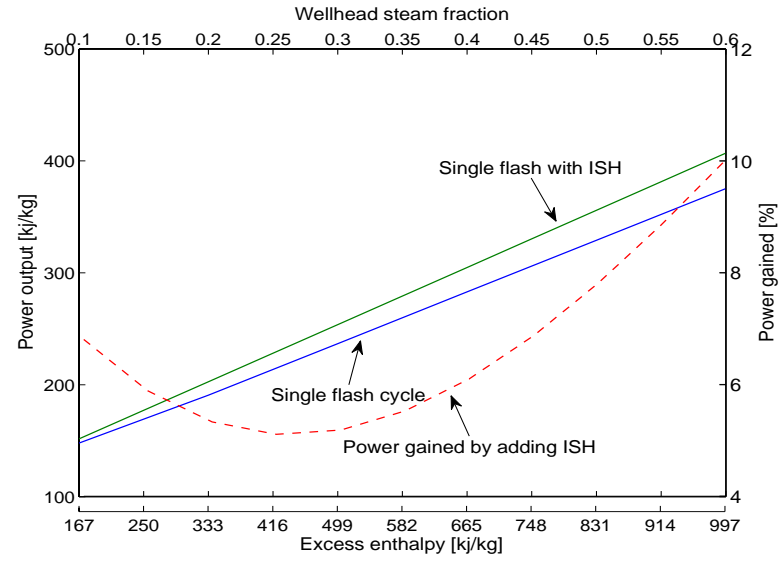

Fig. 8 Effect of increasing steam fraction on net power output.
Net power reduction in steam fraction lower that 0.25 can be explained by figure 9 which shows the effect of varying steam fraction on optimized separation pressure for both single flash and single flash with super heater design. As revealed from the study, optimized separator pressure for both cycles increased with increasing steam fraction but in steam fractions higher than 0.25 , separator pressure of single flash cycle was fixed and could not rise anymore. This is because of the quality limit of exhaust steam of turbine outlet which is assumed not to get lower than 0.85. As described, adding super heater results in increasing turbine exhaust quality of new design and therefore, separator pressure of single flash with super heater can be raised and further optimized. This higher optimized separator pressure of new design results in increasing percentage power gained by single flash cycle with super heater in higher steam fractions.

\subsection{Results of exergy analysis}

Exergy analysis of single flash cycle with super heater for optimum design case of $260^{\circ} \mathrm{C}$ has been presented in this section. Results of exergy assessment for different components are tabulated in table 3. Also figure 8 illustrates exergy destruction rate of each component, graphically. As noticed, $33.69 \%$ or one third of the total losses is attributed to reinjection due to high temperature of separated brine in stage (4). It shows that it is a valuable energy source that can be recovered through adding more flashing stages or other heat extraction processes. The exergy destruction rate of other equipments like condenser, super heater and separator with 65.21, 44.56 and $42.60(\mathrm{~kW})$ are the main losses after reinjection. The lowest exergy losses of 18.49 (kW) shows high performance efficiency of turbine in single flash cycle with super heater design. Also, the highest exergy efficiency of super heater, $97.77 \%$ results in good heat transfer processes between hot and cold streams of heat exchanger.

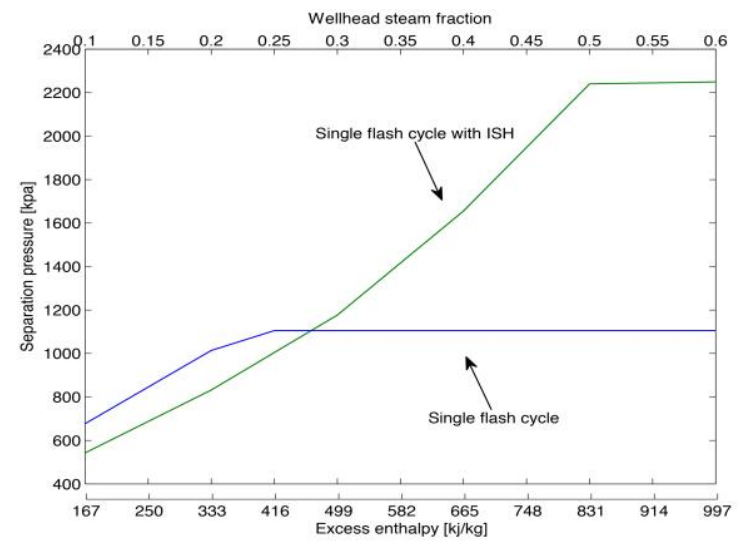

Fig. 9 Effect of increasing steam fraction on the separator temperature. 
Table 3

Exergy efficiencies and exergy destruction rate for single flash cycle with super heater, $\mathrm{T} 1=260^{\circ} \mathrm{C}$.

\begin{tabular}{lllll}
\hline Component & Exergy efficiency (\%) & Exergy loss (kW/(kg/s)) & $\boldsymbol{\eta}_{\mathbf{I}}$ & - \\
\hline Separator & 85.68 & 42.60 & - \\
Super heater & 97.77 & 44.56 & - \\
Turbine & 86.55 & 18.49 & - \\
Reinjection & - & 86.82 & - \\
Condenser & 96.23 & 65.21 & - \\
Single flash cycle & - & - & - \\
Single flash with sh & - & - & 33.1 \\
\hline
\end{tabular}

Finally, performance evaluation of new design based on second-law efficiency showed that $35.77 \%$ of exergy that entered the plant was converted to power and $64.23 \%$ of the total input exergy is lost.

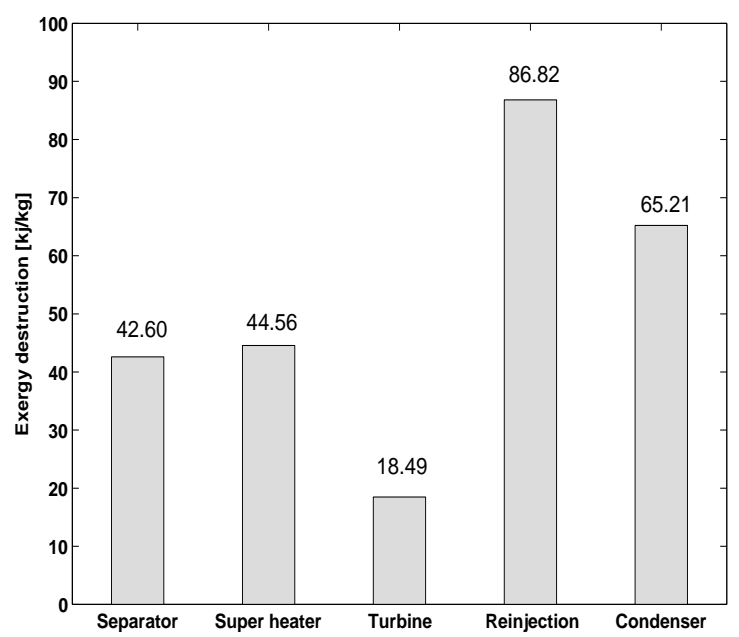

Fig 10. Exergy destruction of different component in single flash cycle with super heater.

\section{Conclusion}

Single flash cycle is the most common type of geothermal power plant worldwide. In this paper, the effect of using a new simple way for utilization of heat contained in hot wellhead geothermal fluid in order to superheat saturated steam entering turbine was presented. Separator pressure, wellhead steam enthalpy and geofluid wellhead temperature are varied to see their effect on net power output and turbine exhaust quality. The results represent increasing net power output from 4 to $8.1 \%$ and reduction of turbine exhaust moisture from 20 to $50 \%$ over a range of source temperature 160 to $260^{\circ} \mathrm{C}$ as compared to basic single flash cycle. This would directly decrease corrosion and water droplet formation on turbine blade which also diminishes operating and maintenance cost of the plant significantly. Moreover, with varying wellhead steam fraction from 0.1 to 0.6 , net power out of single flash cycle with super heater decreased but in steam fraction higher than 0.25 , net power output started to increase and finally gained up to $10 \%$ more power when compared to basic single flash cycle for wellhead geofluid with steam fraction of 0.6 .
Increasing net power output of single flash cycle with super heater is as a result of fixing optimal separator pressure of single flash cycle in higher steam fraction than 0.25 for wellhead fluid due to turbine exhaust quality limit of 0.85 . Results of second law assessment reveal that main losses of exergy are associated with reinjection, condenser, super heater and separator, respectively. Finally, overall plant second-law efficiency of single flash cycle with super heater was calculated $35.77 \%$ which is increased approximately $3 \%$ as compared to single flash cycle.

\section{Nomenclature}

P Pressure, $\mathrm{kPa}$

h Specific enthalpy, kj/kg

$\mathrm{x} \quad$ Vapour content

$\mathrm{T} \quad$ Temperature, ${ }^{\circ} \mathrm{C}$

S Entropy, kj/kg

W Output work, kW

m Mass flow rate, $\mathrm{kg} / \mathrm{s}$

$\dot{\mathrm{Q}} \quad$ Heat transfer rate, $\mathrm{kW}$

ex Specific exergy flow, $\mathrm{kj} / \mathrm{kg}$

E $\quad$ Exergy rate, kW

\section{Greek letters}

$\eta \quad$ Efficiency

$\alpha \quad$ Cold stream outlet state after heat exchanger

$\Delta \quad$ Difference

Subscripts

0 Reference condition

1...25 State number

br Brine

st $\quad$ Steam

ext Extraction

cond Condenser

cyc Cycle

dry Dry

wet Wet

pp Pinch point

sep Separator

turb Turbine

total Total

in Inlet

out Outlet 
sh

sat

Super heater

Saturation

\section{References}

Abas, N., A. Kalair, and N. Khan. (2015) Review of Fossil Fuels and Future Energy Technologies. Futures , 69, 31-49.

Ahmad, M., M. Casey, and N. Srken. (2009) Experimental Assessment of Droplet Impact Erosion Resistance of Steam Turbine Blade Materials. Wear, 267(9-10), 1605-1618.

Bidini, G., U. Desideri, F. Maria, A. Baldacci, R. Papale, and F. Sabatelli. (1998) Optimization of an Integrated Gas Turbine-Geothermal Power Plant. Energy Conversion and Management, 39(16), 1945-1956.

Chamorro, C., M. Mondjar, R. Ramos, J. Segovia, M. C. Martn, and M. Villaman. (2012) World Geothermal Power Production Status: Energy, Environmental And Economic Study Of High Enthalpy Technologies. Energy, 42(1), 10-18.

Coskun, C., Oktay, Z. and Dincer. I. (2011) Modified Exergoeconomic Modeling Of Geothermal Power Plants. Energy, 36(11), 63586366.

Dada, A., Ztrk,R. and Kr. Bekdemir. (2005) Thermodynamic Evaluation of Denizli Kzldere Geothermal Power Plant and Its Performance Improvement. Energy Conversion And Management, 46(2), 245-256.

Dincer, I. (2007) Exergetic and Sustainability Aspects of Green Energy Systems. Clean Soil Air Water, 35(4), 311-322.

Dincer, I., and Zamfirescu. C (2012) Renewable-Energy-Based Multigeneration Systems. International Journal of Energy Research, 36(15), 1403-1415.

DiPippo, R. (2015) Geothermal Power Plants: Evolution and Performance Assessments. Geothermics, 53, 291-307.
DiPippo, R. (2012) Single-Flash Steam Power Plants.Geothermal Power Plants: 81-109. Elsevier BV

Jalilinasrabady, S., R. Itoi, P. Valdimarsson, G. Saevarsdottir, and H. Fujii. (2012) Flash Cycle Optimization Of Sabalan Geothermal Power Plant Employing Exergy Concept. Geothermics, 43, 75-82.

Mathieu-Potvin, F. (2013) Self-Superheating: A New Paradigm For Geothermal Power Plant Design. Geothermics, 48, 16-30.

Matlab. (2010) MATLAB (V7.10.0-R2010a). Natick, Massachusetts, United States.: The MathWorks Inc.

Phillips, J. (2010) Evaluating the Level and Nature of Sustainable Development for A Geothermal Power Plant.Renewable and Sustainable Energy Reviews, 14(8), 2414-2425.

REFPROP,. (2010) Transport Properties Database (REFPROP V9.0). National Institue of Standards and Technology (NIST).

Rosen, M., and I. Dincer. (2001) Exergy as the Confluence Of Energy, Environment And Sustainable Development. Exergy, An International Journal, 1(1), 3-13.

Rosen, M., and I. Dincer. (2004) Effect of Varying Dead-State Properties on Energy and Exergy Analyses Of Thermal Systems. International Journal of Thermal Sciences, 43(2),121-133.

Wang, J., J. Wang, Y. Dai, and P. Zhao. (2015) Thermodynamic Analysis and Optimization of a Flash-Binary Geothermal Power Generation System. Geothermics 55, 69-77.

Zarrouk, S., and M. Purnanto. (2015) Geothermal Steam-Water Separators: Design Overview. Geothermics, 53,236-254.

Zhou, C. (2014) Hybridisation of Solar and Geothermal Energy In Both Subcritical And Supercritical Organic RankineCycles.Energy Conversion And Management, 81,72-82. 